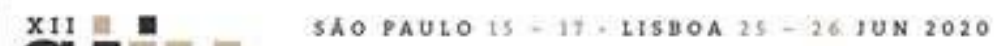

\section{RESSIGNIFICANDO OS ESPAÇOS LIVRES Um Diagnóstico da Comunidade do Gengibre em Fortaleza-CE}

\author{
Meaning free paces \\ A diagnosis of the Ginger Community in Fortaleza-CE
}

\author{
A. Lizandra Santos Magalhães \& B. Clarisse Costa Silva \& \\ C. Vítor Domício de Meneses \\ Centro Universitário UniFanor, Brasil \\ lizandrasantos619@gmail.com \\ clarissecostasilva@gmail.com \\ domiciomeneses@yahoo.com.br
}

\section{RESUMO}

O presente artigo foi estruturado, inicialmente, por meio de análise geral sobre assentamentos precários, suas problemáticas, densidade populacional, tendo como questão principal os espaços públicos. O estudo abrange os problemas urbanos nas áreas de risco, como falta de infraestrutura, informalidade das habitações, espaços livres, assim como a influência na qualidade de vida da população. Houve a elaboração do diagnóstico da comunidade de Gengibre em Fortaleza-CE, apresentando o local, ações realizadas e questionamentos de pesquisa e, em seguida, as considerações finais sobre a coleta de dados e conclusão sobre o trabalho.

Palavras-chave: comunidade, favela, Gengibre, espaços públicos.

Linha de investigação: Cidade e projeto.

Tópico: Estudos metropolitanos e territoriais.

\section{ABSTRACT}

This article was initially structured through a general analysis of precarious settlements, their problems, population density, with public spaces as the main issue. The study covers urban problems in areas at risk, such as lack of infrastructure, informal housing, free spaces, as well as the influence on the population's quality of life. The diagnosis of the Ginger community in FortalezaCE was elaborated, presenting the location, actions carried out and research questions and, then, the final considerations on data collection and conclusion on the work.

Keywords: community, slum, Ginger, public spaces.

Research line: City and project.

Topic: Metropolitan and territorial studies. 



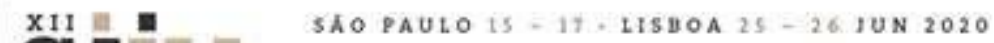

A requalificação de um espaço público faria com que os moradores se apropriassem de maneira adequada do ambiente, utilizando-o não apenas para a construção de moradias, mas, também, criando áreas de lazer, entretenimento e socialização? Por se tratar de um bairro periférico e de uma ZPA 1, isso dificulta a possibilidade de a comunidade possuir espaços públicos urbanizados e infraestrutura urbana de qualidade?

O objetivo desta pesquisa é, portanto, realizar um diagnóstico da Comunidade de Gengibre, em Fortaleza -CE, analisando as deficiências urbanísticas dos espaços públicos e da infraestrutura local, examinando formas de apropriação, carências e potencialidades, estudando os motivos pelos quais esses espaços são urbanisticamente inapropriados.

A metodologia possibilitante da realização do trabalho constituiu-se através do contato com a comunidade, observação das deficiências urbana e de infraestrutura do local, fazendo-se fotografias que foram posteriormente analisadas. O passo seguinte foi a aproximação com os moradores, através de Fórum Comunitário realizado pelo Programa Extensivo Bons Vizinhos, no dia 30/03/2019, o qual teve como objetivo reunir o máximo de moradores possível para debater as necessidades do local e propor futuras modificações, a curto, médio e longo prazos. Outra abordagem utilizada foi a realização de Oficinas de Desenhos com crianças da Comunidade, evento esse organizado pelos alunos do Curso de Arquitetura e Urbanismo, integrantes do referido Programa de Extensão, havendo sido realizada, ainda, uma Feira das Profissões, durante a qual os participantes foram solicitados a fazer desenhos, partindo da temática "Como eles visualizam o Gengibre e como queriam que a comunidade fosse".

\section{Fundamentação Teórica}

O Instituto Brasileiro de Geografia e Estatística (IBGE) emprega o conceito de aglomerado subnormal, a fim de caracterizar um conjunto habitacional constituído de, no mínimo, 51 unidades habitacionais carentes de serviços públicos essenciais. A identificação atende aos seguintes critérios: ocupação de forma densa e desordenada, invasão de terreno alheio, público ou privado, sem acesso a serviços públicos básicos (IBGE, 2010).

Para a Organização das Nações Unidas (ONU), favela é uma área com acesso inadequado a água potável, ausência de infraestrutura de saneamento básico, alta densidade construída, baixa qualidade das unidades habitacionais e problemas relativos à sua propriedade legal (ONU, 2000).

As áreas periféricas conhecidas como favelas ou comunidade estão relacionadas à estrutura local, que tem como características habitações aglomeradas, implantadas em locais com passagens estreitas, vielas, com vias carroçáveis, degradada, sem serviço público e, quando possui algum, o mesmo encontra-se em situação precária, ausente de manutenção e/ou até mesmo sendo utilizado de maneira ilegal (água, luz, esgotamento sanitário e pluvial, escola, local para atendimento médico, transporte, lazer). As construções são realizadas de forma autônoma, com a utilização de materiais recicláveis e de pouca durabilidade.

\subsection{Outras definições}

Os "interstícios urbanos" são nada mais que espaços públicos e semi-públicos, como parques, praças, lagos e terrenos livres, os quais devem prestar-se ao uso coletivo, mas se tornam inapropriados, por não se encontrarem em estado de utilização adequada. 


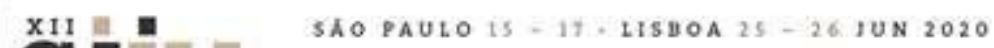

"Interfaces urbanas", por sua vez, é expressão que diz respeito às estruturas físicas, existindo delimitação no espaço, comportando os interstícios urbanos e também incluindo os espaços fechados.

"Espaço livre" é, tal como a expressão o indica, um espaço urbano ao ar livre, onde se pode desenvolver múltiplas atividades dinâmicas e/ou de descanso e lazer, como caminhadas, exercícios, brincadeiras, atividades esportivas, servindo também como áreas de descontração.

Por se tratarem de locais públicos, devem oferecer segurança e conforto, mantendo-se a preocupação com a necessária separação da calçada ou passeio em relação às ruas e aos veículos (Deise e Márcio, 2016).

Segundo Galender (2005), os espaços livres apresentam pontos favoráveis que podem ser trabalhados de duas formas: caráter sociocultural e aspectos biofísicos. O caráter sociocultural está ligado às atividades humanas que nelas possam ser desenvolvidas, como lazer, passeios e recreação. A abordagem biofísica refere-se à integração dos ecossistemas, promoção da biodiversidade, melhoria da drenagem pluvial e criação de microclimas.

\subsection{A imagem da favela: uma construção social}

O cenário das favelas se expandiu por todo o Brasil, sendo áreas invadidas por pessoas que se encontram sem alternativas para onde ir ou morar. Dessa maneira as comunidades apresentaram um evidente aumento populacional, sendo constituídas sobretudo por pessoas de etnia negra. Os melhores exemplos disso, no Brasil, são a Favela da Rocinha, no Rio de Janeiro, e a favela de Paraisópolis, em São Paulo.

Tomando-se como exemplo Paraisópolis, sabemos que é a segunda maior favela de São Paulo, localizada em um assentamento informal consolidado. Sua população gira em torno de $100 \mathrm{mil}$ habitantes, sendo superior ou equivalente a maior parte dos Municípios do Estado de São Paulo. Entretanto, por conta da sua expansão, Paraisópolis é muito mais do que um bairro ou fragmento urbano, sendo, sim, uma cidade, com suas características próprias. Está localizada na Zona Sul de São Paulo, sendo administrada pela Subprefeitura do Campo Limpo.

As casas em Paraisópolis são construídas verticalmente, com características semelhantes à Comunidade do Gengibre, em Fortaleza-CE, possuindo becos e vielas, casas com construções em alvenaria, materiais recicláveis, escadas com avanços na circulação e rampas com inclinações acentuadas.

Entretanto, em Paraisópolis não há espaços públicos de qualidade, possuindo espaços abertos, que não são ocupados, isso tornando o cenário semelhante ao da Comunidade do Gengibre. 


\section{XII $=$ SAOPAULO $15-17.21580 \mathrm{~A} 25-26.10 \mathrm{~N} 2020$ SIIU. \\ Seminário Internacional de \\ Seminario Internacional de Investigaço em Urbanismo Investigación en Utbanismo}

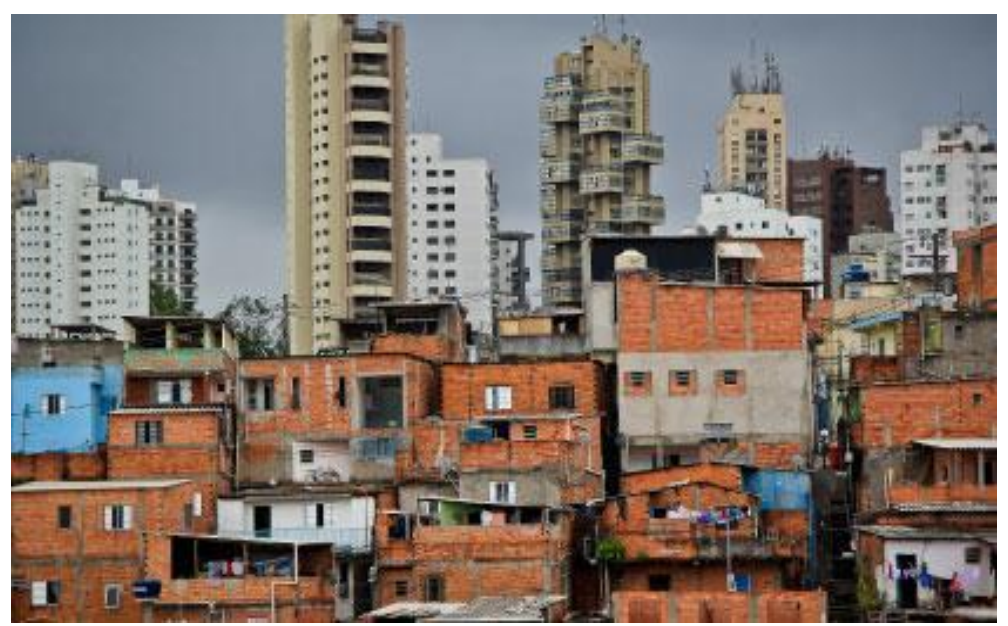

Fig. 01 Favela de Paraisópolis, São Paulo: Google imagens (2020).

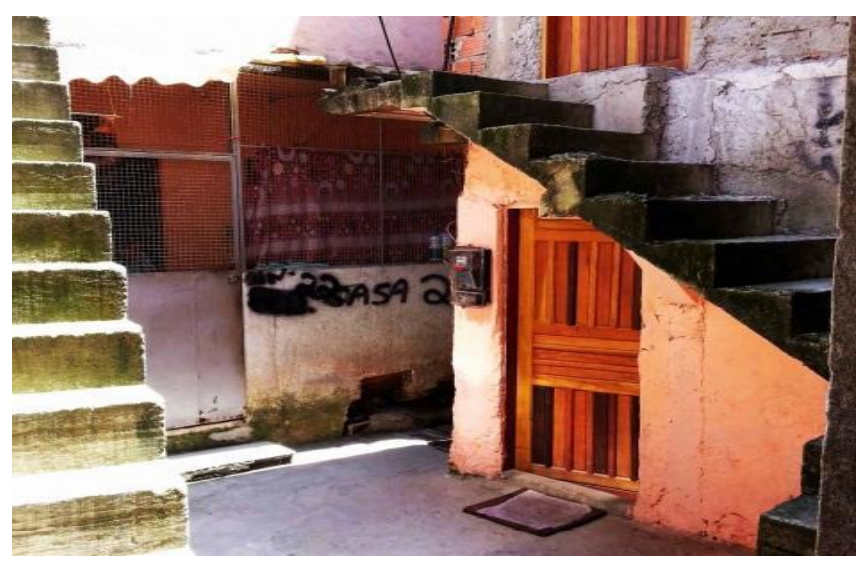

Fig. 02 Escadas na área de circulação. Paraisópolis: Eduardo Pizarro (2014).
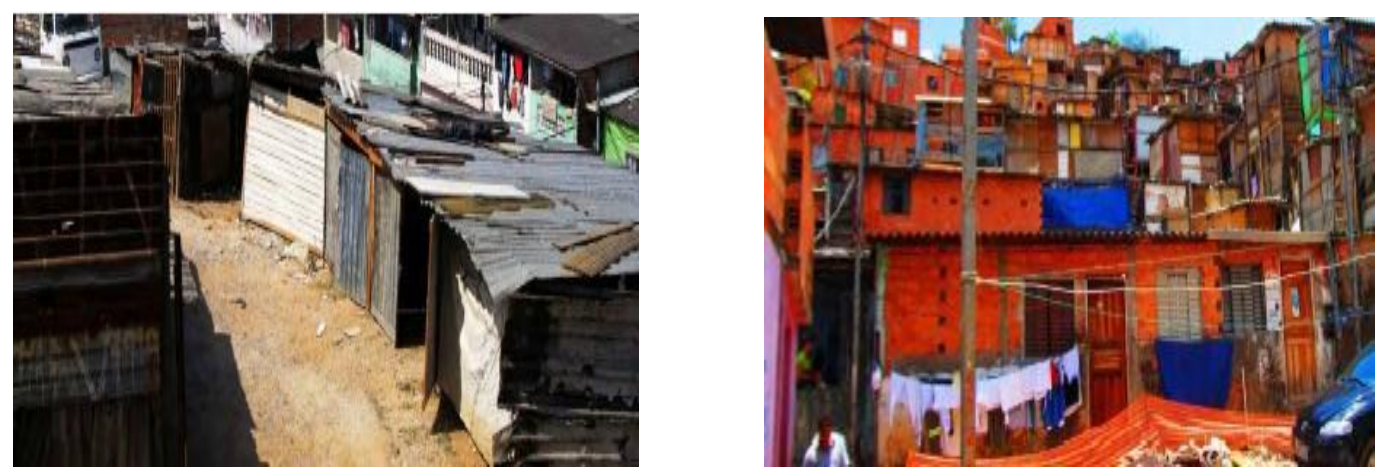

Fig. 03 Construções com materiais recicláveis e em alvenaria. Paraisópolis, São Paulo: Eduardo Pizarro (2014). 


\section{XII $\quad$ SAOPAULO $15-17.21580 A 25-26.10 N 2020$ \\ SIIU.}

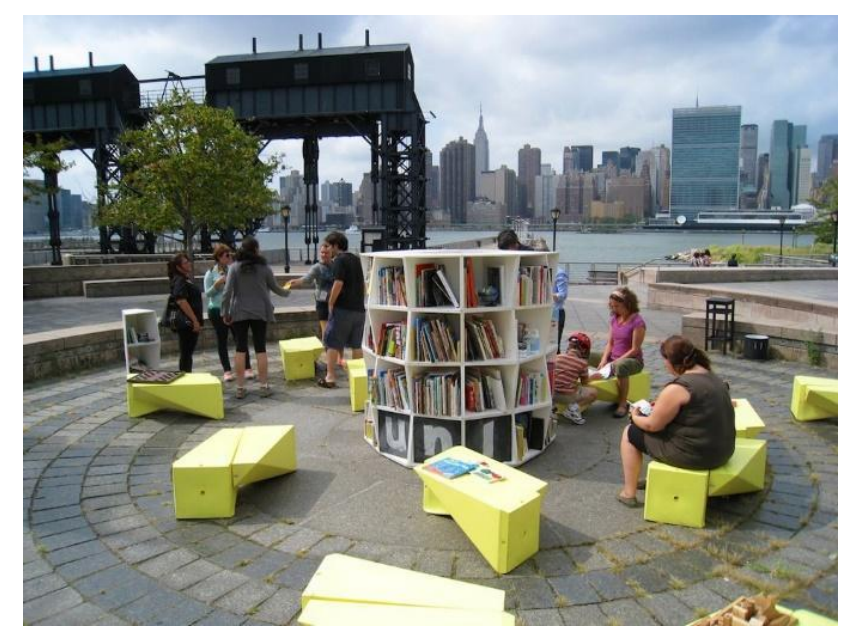

Fig. 05 Biblioteca nos espaços públicos, Nova York: Google imagens (2011).

\subsection{Parklets em São Paulo}

Os "parklets" são propostas de áreas de convivência nas ruas. Foram implantados em São Paulo, em 2014, sendo responsável pela iniciativa o Presidente do Instituto de Mobilidade Verde (IMV), Lincoln Paiva, após conhecer, em viagem aos Estados Unidos, em 2010, conheceu os parklets, em São Francisco, trazendo a proposta para o Brasil.

Os parklets podem ser produzidos com materiais de baixo custo, são de rápida e prática montagem. Podem-se utilizar pinturas no chão, para realçar e embelezar o local, os quais se constituem como proposta para a criação de espaços de leitura, como a Biblioteca Comunitária na Rua Mateus Grou, São Paulo, Capital.

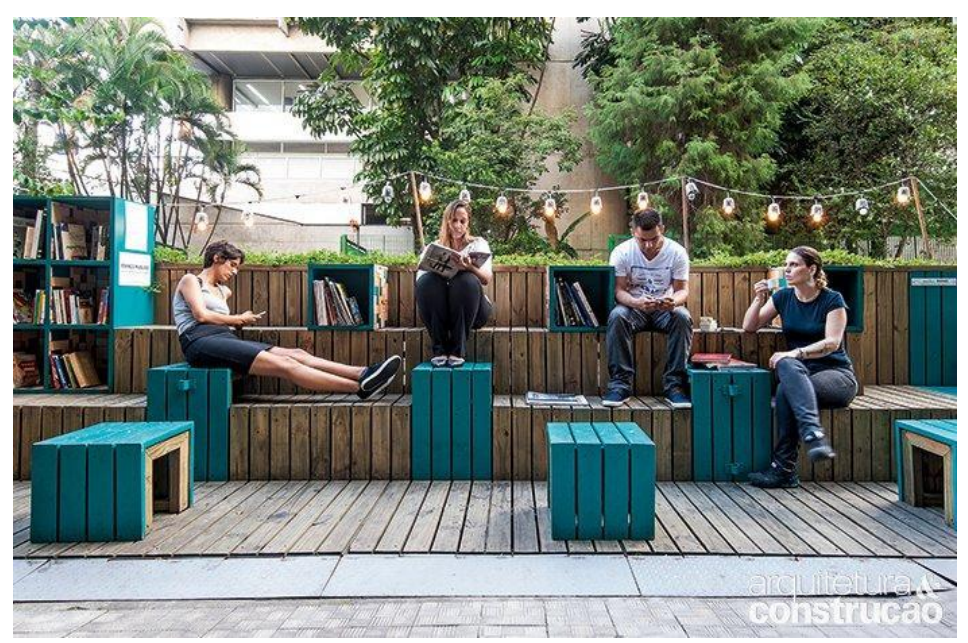

Fig. 06 Parklet participativo "Suri”, na Rua Mateus Grou, São Paulo. Com biblioteca comunitária, arquibancada para shows, equipamentos para animais de estimação, bicicletário, guarda-sol, paisagismo com plantas comestíveis: Zoom Arquitetura (2014). 


\section{XII \\ Seminário Internacional de \\ Seminario Internacional de Investigaç̃o em Urbanismo

\subsection{Parque infantil Pixeland, Mianyang, China}

Trata-se de um projeto de revitalização e embelezamento do espaço público, implantado ao ar livre, possuindo trabalho de paisagismo, parque infantil e servindo como local público de lazer. 0 projeto tem como inspiração o mundo tecnológico, digital de pixels. É multifuncional, cada pixel possuindo sua própria característica e função, tornando-se uma área atrativa e lúdica. Possui uma praça com áreas de relaxamento, áreas para piquenique com mobiliário urbano, mesas e bancos de assento, projetadas em vários níveis, de forma a criar uma topografia artificial e lúdica.

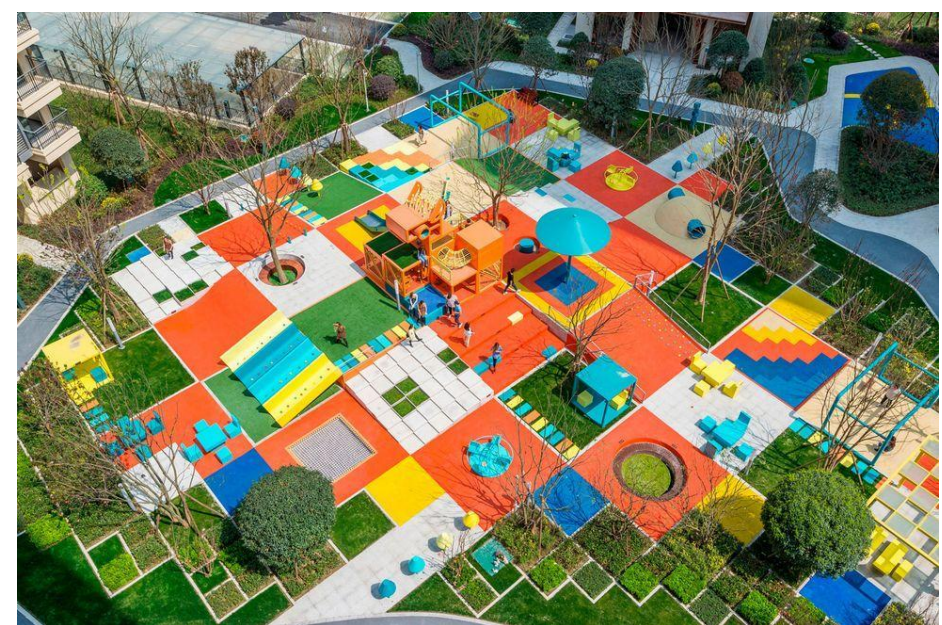

Fig. 07 Parque infantil Pixeland, Mianyang China. Fonte: Archdaily (2019).

\section{Contexto e justificativa}

Mundialmente, dos 7 bilhões de habitantes (ONU, 2011), cerca da metade (ONU, 2000) reside em meio urbano. Dessa população urbana, a parcela de $29 \%$, isto é, cerca de 1 bilhão de habitantes (Davis, 2007), concentra-se em assentamentos irregulares e desprovidos de condições mínimas de salubridade, saneamento, serviços e equipamentos, as denominadas Favelas.

Entre 1960 e 1970, no Brasil as casas nas periferias eram construídas com materiais de baixo custo, precários e dotados de pouca resistência e durabilidade. A partir de 1980, as favelas passaram por algumas transformações, recebendo benefícios públicos, como instalações de energia elétrica, água e esgoto.

Os barracos, que eram apenas de madeira, passaram a ser construídos em alvenaria, possuindo também revestimento com argamassa, pintura nas paredes e cerâmica no chão. Apesar do seu dinamismo físico e urbano, a favela abriga, em um mesmo barraco, famílias ao longo de gerações.

\subsection{Cidade Contemporânea (superpopulação e consequências)}

Atualmente vivenciam-se situações críticas decorrentes da problemática das cidades e do meio urbano. Um dos problemas é o alto índice de aglomeração populacional na cidade, com as questões disso decorrentes, sobretudo quando se considera que a população mundial deve 


\section{XII

crescer em 2 bilhões de pessoas, nos próximos 30 anos, passando dos atuais 7,7 bilhões de indivíduos para 9,7 bilhões em 2050, de acordo com o relatório das Nações Unidas lançado no dia 17/06/2019 (ONU, 2019).

Essa situação crítica é vivenciada também pelo Brasil. O IBGE divulga as estimativas das populações residentes nos 5.570 municípios brasileiros, com data de referência em $1^{\circ}$ de julho de 2019. Estima-se que o Brasil tenha 210,1 milhões de habitantes e uma taxa de crescimento populacional correspondente a $0,79 \%$ ao ano, apresentando queda do crescimento quando comparado ao período 2017/2018, conforme a Projeção da População 2018 (IBGE, 2019), o mesmo podendo-se dizer quanto à cidade de Fortaleza-CE., que possui grande densidade populacional, sendo considerada a $5^{\circ}$ cidade mais populosa do Brasil, com 2.669.342 habitantes (IBGE, 2019).

\subsection{Patologias ambientais e socioeconômicas da cidade de Fortaleza-CE}

Em relação ao território cearense tem-se registrado constantemente ocorrências de desastres, tais como, por exemplo, aqueles motivados pelas enxurradas e inundações, ocorridas nos anos de 2004, 2008 e 2009, verificando-se, nos anos de 2012 a 2016, estiagens e secas.

Segundo a Defesa Civil Municipal de Fortaleza, foram detectadas 89 (oitenta e nove) áreas de risco, envolvendo 21.345 (vinte e um mil trezentos e quarenta e cinco) famílias, com registro de ocorrências como alagamento e inundação e deslizamentos de terras e soterramento.

Observando-se que, para muitas pessoas, é difícil a obtenção de uma moradia digna nas grandes capitais, por conta da especulação imobiliária a qual faz com que as populações de baixa renda não tenham condições de arcar com o preço de terrenos e imóveis, sendo este um dos fatores que fazem com que muitas pessoas passem a morar em áreas de risco, como é o caso dos moradores da Comunidade do Gengibre, que residem em uma Zona de Preservação Ambiental 1 (ZPA1), próximo ao bairro Dunas, considerado bairro de luxo, onde localizam-se condomínios, mansões e um Centro Universitário.

\section{Diagnóstico da Comunidade do Gengibre}

A Comunidade do Gengibre está localizada em Fortaleza-CE, próximo ao Centro Universitário UniFanor Wyden, Dunas. Os moradores da comunidade enfrentam dificuldades de acesso aos serviços de saúde, possuindo baixo nível de escolaridade e empregabilidade no mercado de trabalho formal.

Muitas das pessoas que moram na comunidade, sobrevivem graças à venda de materiais recicláveis, possuindo renda baixa, incapaz de suprir todas as necessidades familiares. A infraestrutura local, apresenta riscos ambientais, como a exposição a esgotos a céu aberto, lixo espalhado pela comunidade, possibilidade de deslizamento de terra.

O Gengibre é uma área carente em assistência, padecendo, os seus moradores, de inúmeras restrições: por ocuparem uma área inapropriada e ilegal, visto ser terreno de preservação 


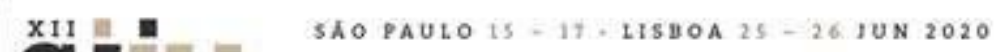 \\ SIiUl $=-$}

permanente de recursos hídricos, são vítimas do descaso das autoridades governamentais, isso implicando que o local não possua infraestrutura habitacional adequada, dada a interdição legal de construções no local, conforme reza a legislação pertinente:

Art.66- São parâmetros da ZPA: I- índice de aproveitamento básico:0,0; II- índice de aproveitamento máximo:0,0; III- índice de aproveitamento mínimo: 0,0; IV- taxa de permeabilidade:100\%; V- taxa de ocupação:0,0; VI- altura máxima da edificação:0,0. (LUOS)

O Gengibre tem como colaboradores os universitários da UniFanor Wyden, por meio do Programa de Extensão Interdisciplinar Bons Vizinhos, responsável pelo desenvolvimento de trabalhos na Comunidade, com crianças, adolescentes, idosos e com as famílias.

O Programa foi implantado em 2012 e, atualmente, é formado por estudantes oriundos de diversos Cursos de diferentes áreas científicas, desenvolvendo atividades externas, com foco no compromisso social, ético e político, junto à comunidade do Gengibre.

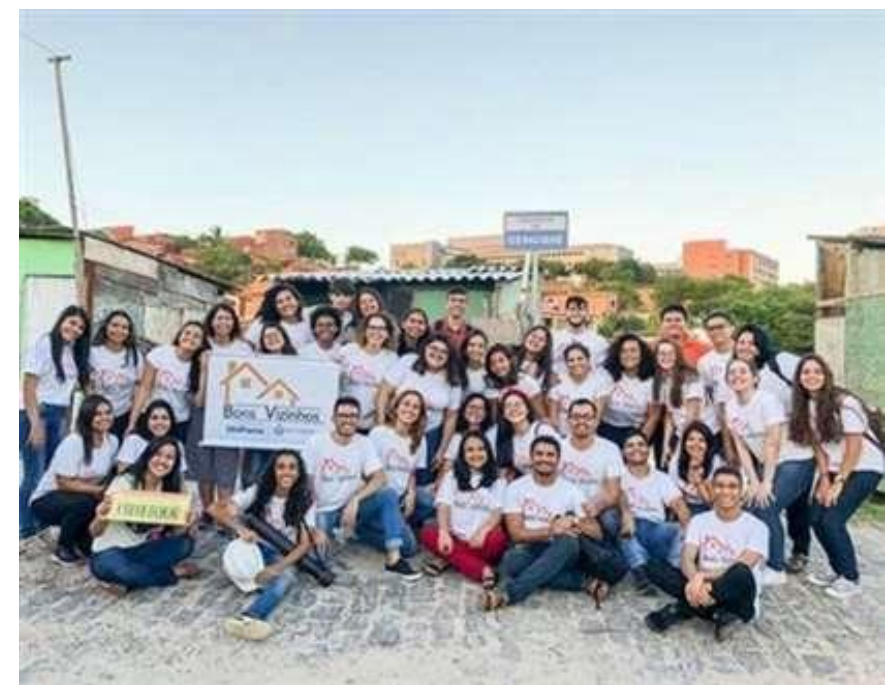

Fig. 08 Programa de Extensão Interdisciplinar Bons Vizinhos: Arquivo Bons Vizinhos (2019). 


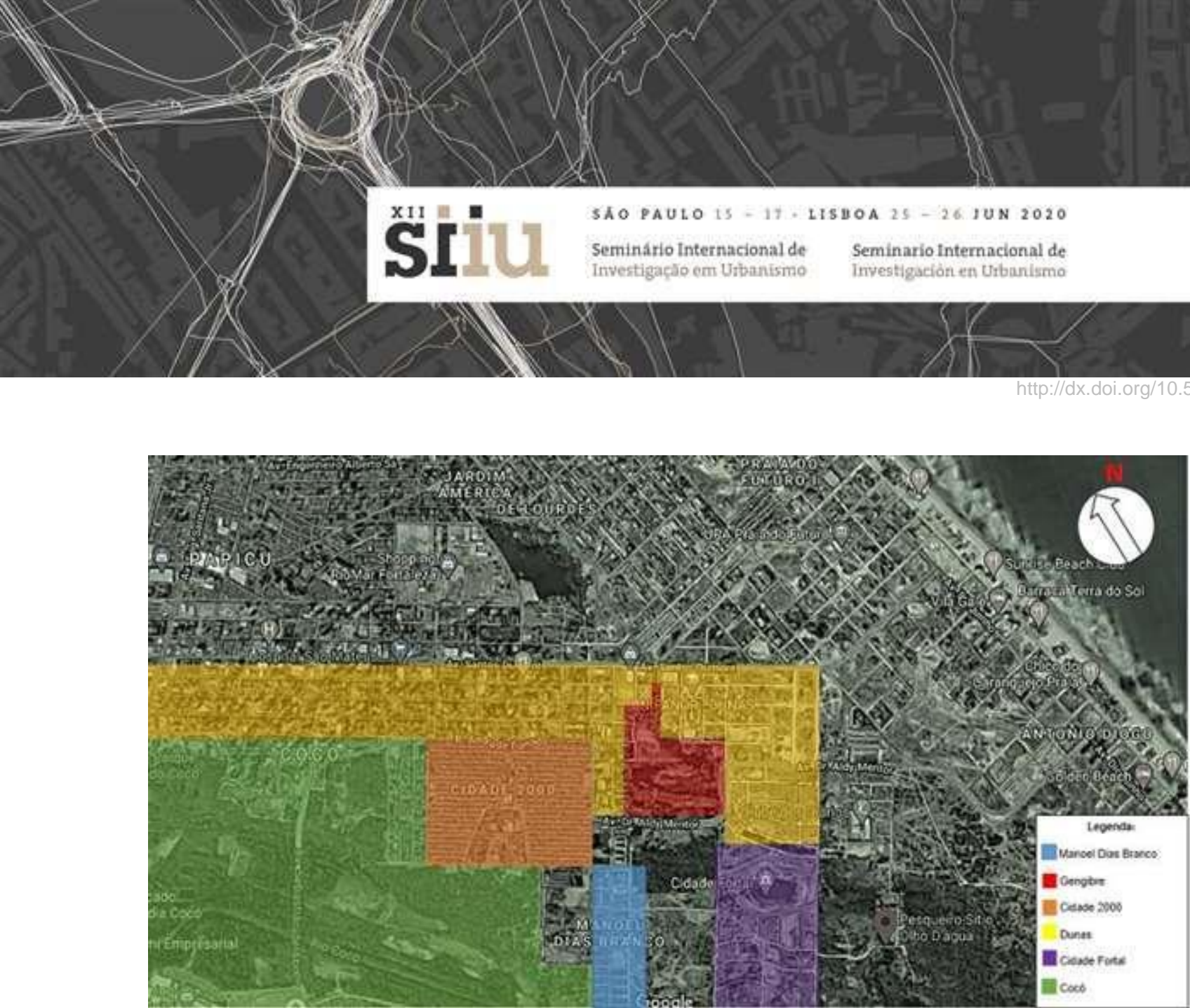

Fig. 09 Foto aérea das principais edificações e limites da comunidade, Fortaleza-CE: Google Maps (2020).

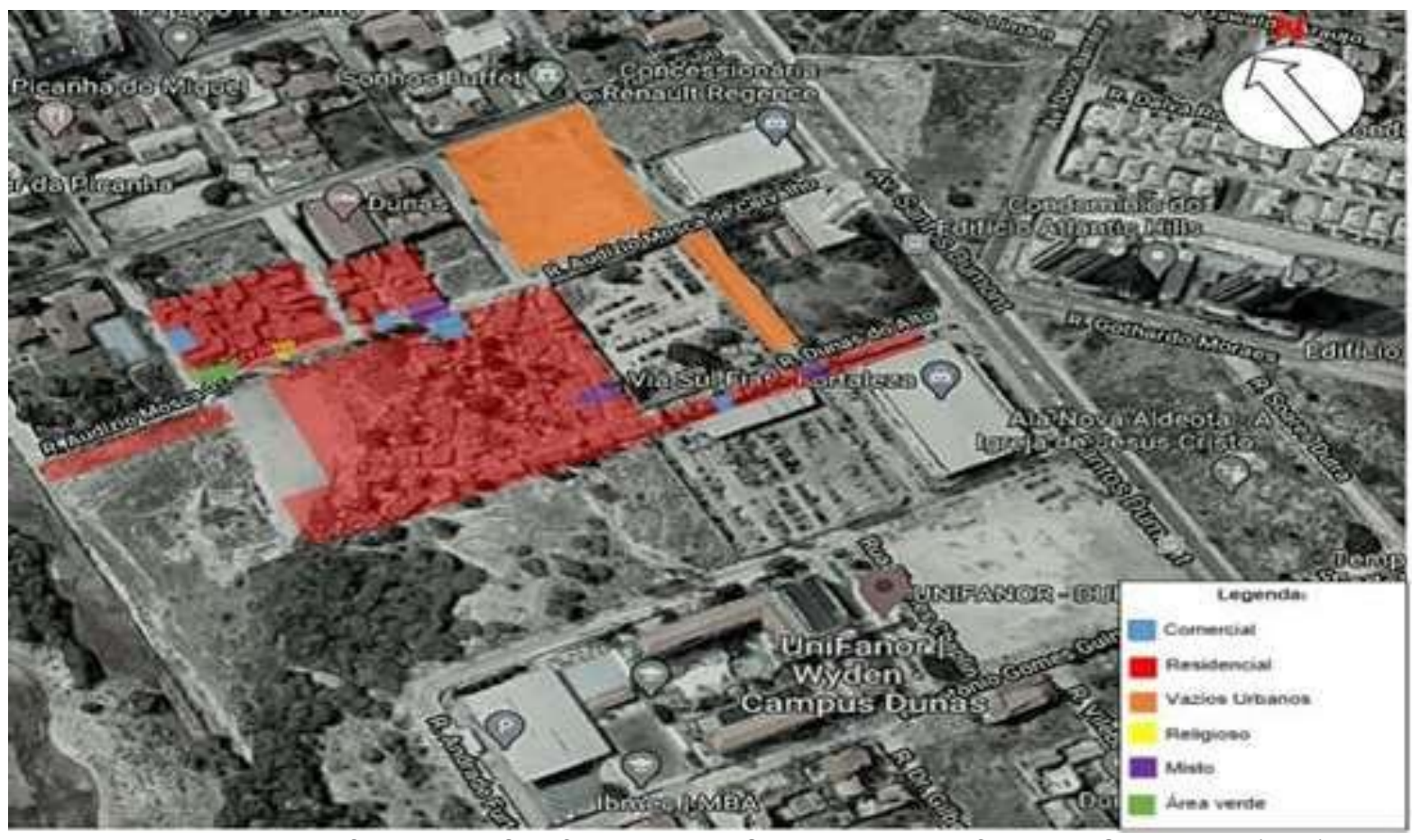

Fig. 10 Mapa de Lei de Uso e Ocupação do Solo Comunidade do Gengibre, Fortaleza-CE. Fonte: Google Maps (2020). 


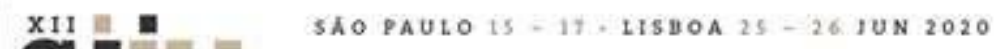

\section{$\begin{array}{ll}\text { Seminário Internacional de } & \text { Seminario Internacional de } \\ \text { Investigaça em Urbanismo } & \text { Investigación en Urbanismo }\end{array}$}

\subsection{Formas de ocupação}
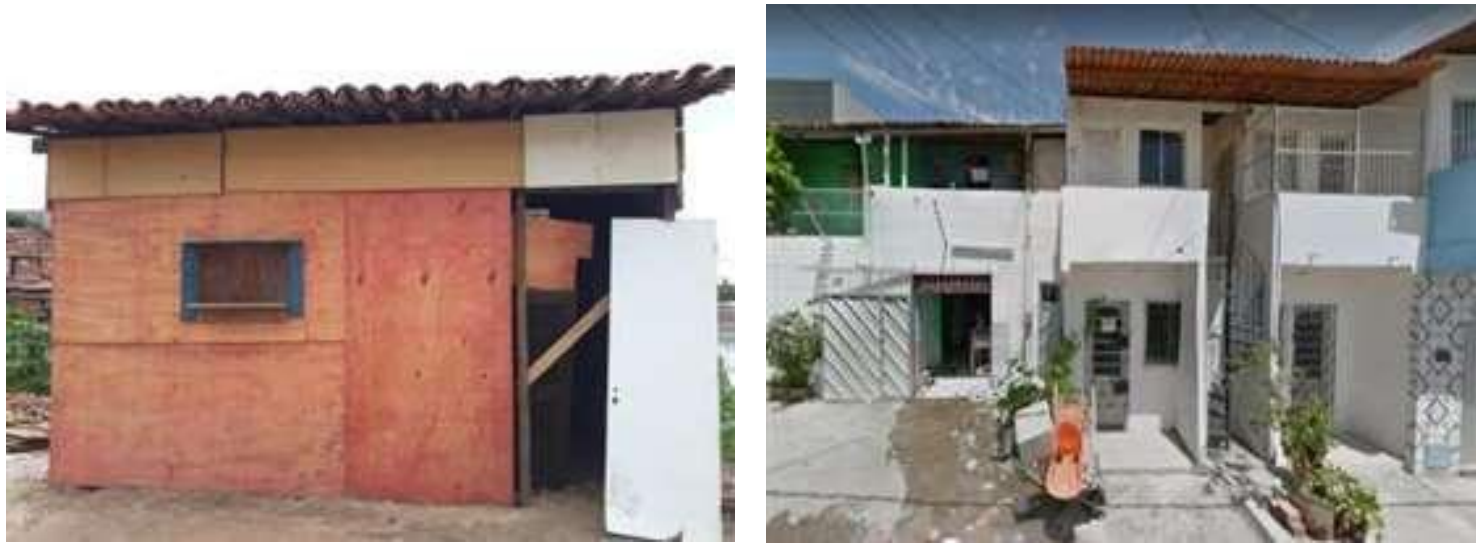

Fig. 11 Casas Comunidade do Gengibre: Arquivo Bons Vizinhos (2020).

As construções da Comunidade são bem diversificadas, existindo algumas casas construídas em alvenaria e, a maioria, de plástico, papelão, madeira prensada, restos de materiais de construção. As residências são divididas em casas, apartamentos de 2 ou 3 pavimentos, erguidos pelos próprios moradores, com avanço de calçadas ou escadas helicoidais que dificultam a circulação. Como mostram as imagens, há, em meio à diversidade de moradias, casas com melhores e piores condições de habitabilidade.

\subsection{Lagoa}
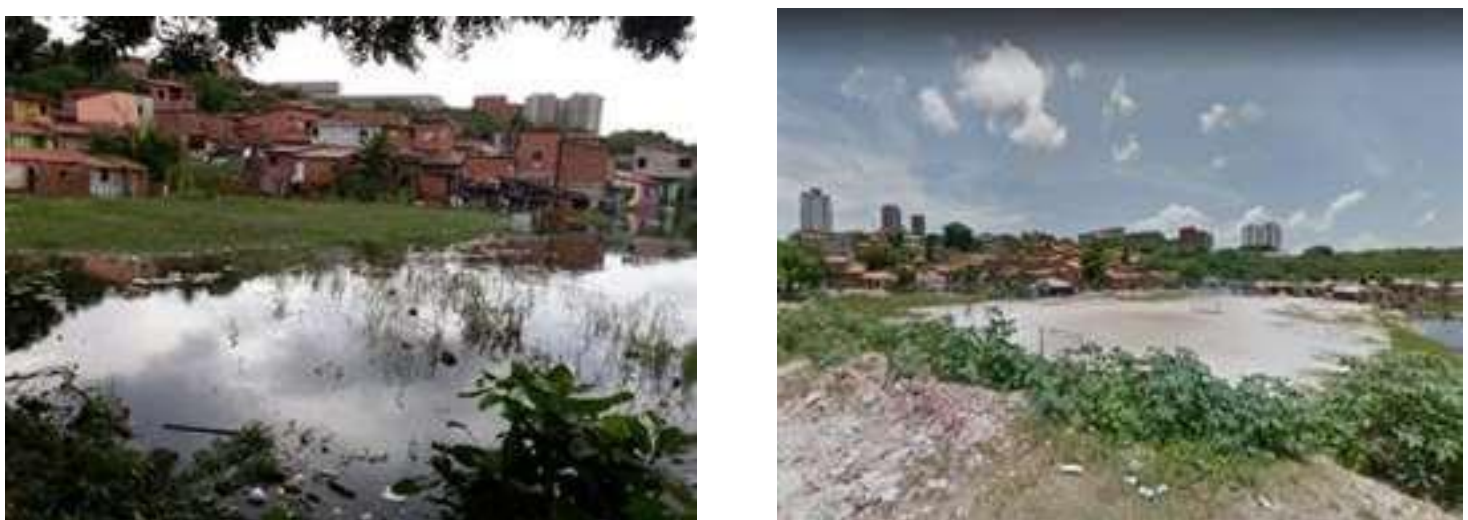

Fig. 12 Lagoa do Gengibre em período chuvoso e escasso: Arquivo Bons Vizinhos (2020).

Um dos fatores de risco bastante discutido é uma lagoa, a qual, em alguns meses do ano está cheia e, em outros, não, isso fazendo com que algumas pessoas se apropriem do espaço e nele ergam suas moradias, servindo também como espaço de lazer, como campo de futebol, quando seca, ou banhos e passeios de jangada, quando cheia. 


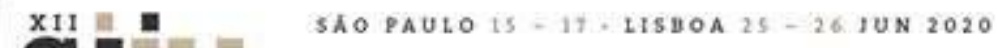 \\ SIIU $=-m$}

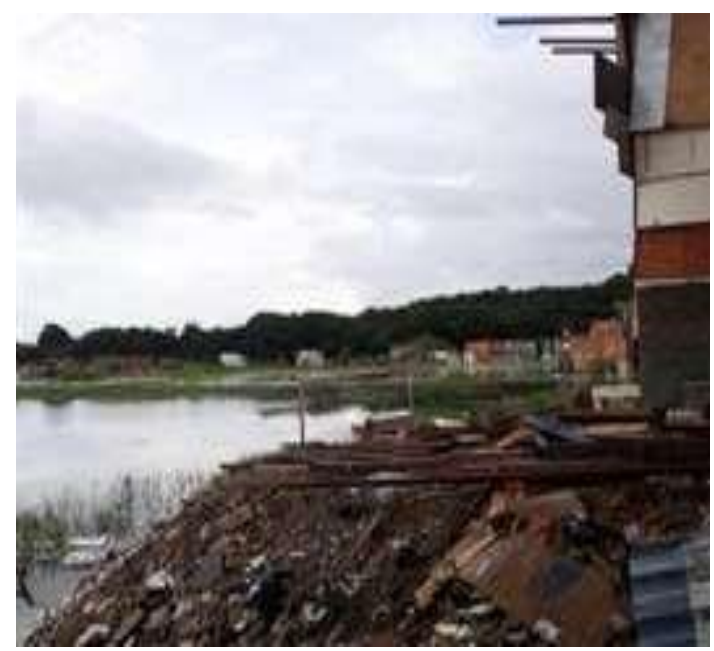

Fig. 13 Entulhos, resíduos dentro e no entorno da lagoa: Arquivo Bons Vizinhos (2020).

Outro problema resulta do acúmulo de lixo em seus arredores, causando poluição e servindo como fonte de doenças. Muitas dessas questões já chegaram aos jornais da cidade, graças aos apelos feitos pelos moradores ou apresentam solicitações, junto à Prefeitura local, de remanejamento espacial da Comunidade, abrindo mão, seus moradores, do apego afetivo à localidade, da memória popular e de suas próprias histórias, no que não foram atendidos, até à presente data, mesmo que, segundo a Defesa Civil, em torno de 77 famílias estejam em situação de risco (O Povo, 2019).

Era anunciado acontecer isso [cheia e alagamento]. A Prefeitura sabia", define Manoel Garcia, conhecido também como "Gereba", líder comunitário da Comunidade do Gengibre. O mesmo reitera a necessidade de que a situação seja resolvida de forma imediata e relata que ainda há pessoas vivendo nas casas no entorno da lagoa, mesmo com a condição da água chegar a cobrir a cintura de um adulto. (O Povo, 2019)

A entrevista abaixo, publicada pelo jornal "O Povo", expõe claramente o discurso de um morador sobre as questões discutidas.

O pessoal diz que a gente não pode morar aqui, diz que é área verde. Como é que é área verde? A gente não tá nem quebrando mato", questiona o operário da Construção Civil Edinaldo Benedito, 26. O verde não está mesmo no chão onde ele ergueu a casa para morar com a mulher e dois filhos. Predomina o tom marrom do fundo da Lagoa do Gengibre, no bairro Manuel Dias Branco, recurso hídrico que sofreu aterramento por volta de 2002, dando lugar a diversos episódios de invasões (O Povo, 2017, p. 01).

Entretanto, pela falta de trabalho e renda fixa, vivenciam-se elevadas taxas de desemprego, quando em comparação aos demais bairros da cidade. Outro fator de grande impacto, enquadrado no âmbito sócio econômico, são os baixos níveis dos indicadores de educação, de saúde e de 


\section{XII $\mathbf{E}$ SAOPAULO IS-17. IISEOA $25-26.10 \mathrm{~N} 2020$ \\ Seminário Internacional de Investigaçăo em Urbanismo \\ Seminario Internacional de investigación en Urbanismo}

acesso às oportunidades que a cidade proporciona aos demais bairros, existindo uma enorme distância entre a realidade econômica, em se tratando da qualificação do tempo/espaço particular às comunidades, e as condições presentes na cidade como um todo (Pizarro, 2014).

A apropriação do território dá-se especificamente para fins de moradia, com elevada densidade habitacional, marcada por alto grau de vulnerabilidade ambiental, como referido.

\subsection{Ruas e Vielas}
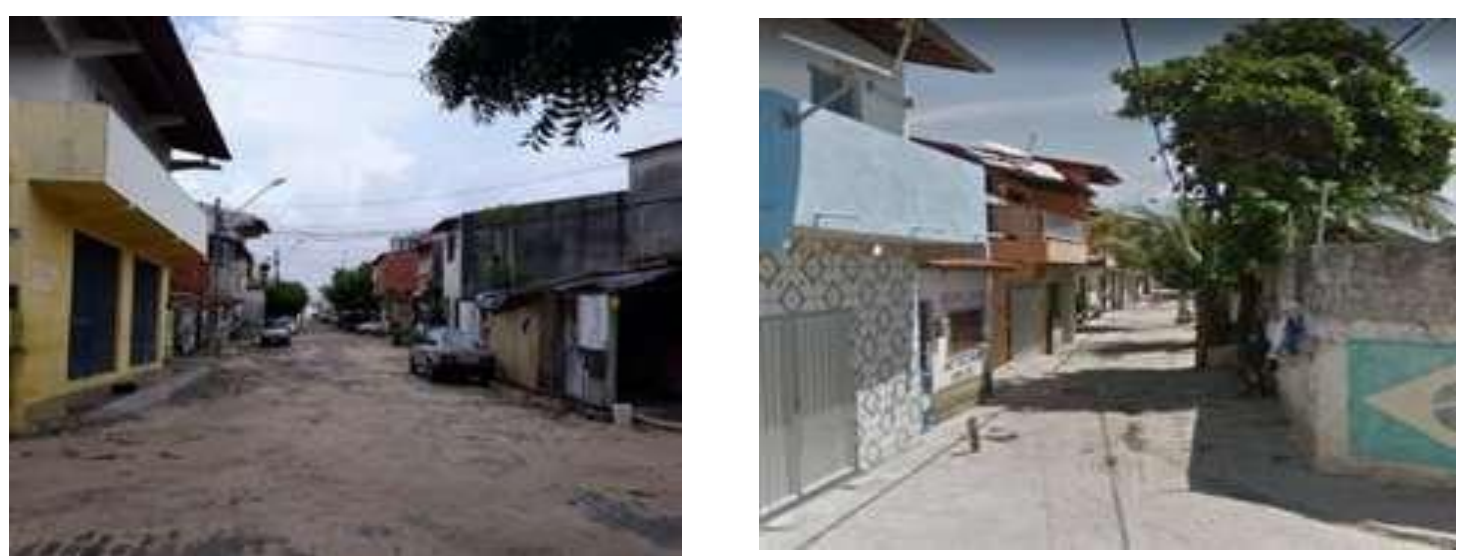

Fig. 14 Ruas e vielas da Comunidade: Arquivo Bons Vizinhos (2020).

O Gengibre é área suburbana onde convivem pessoas em extrema pobreza e outras, investidas de melhores condições econômicas, havendo divisões na comunidade, conhecidas entre eles como "parte de cima" e "parte de baixo", isso gerando rivalidades entre facções.

A Comunidade possui ruas largas e outras estreitas, dificultando o acesso de transportes em determinados locais, isso gerando barreiras de fluxos. Em suas ruas, há rampas bastante inclinadas, sem nenhum suporte de apoio, as quais, quando em período chuvoso, tornam-se ainda mais perigosas à circulação, pois são causas de deslizes, principalmente por parte de pessoas com pouca coordenação motora ou sem nenhuma, como idosos, cadeirantes e individuos com alguma limitação temporária.

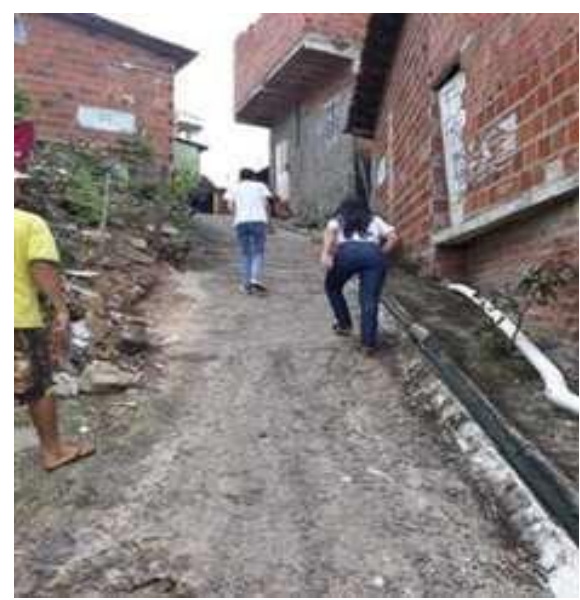

Fig. 15 Acessos, rampas com falta de acessibilidade: Arquivo Bons Vizinhos (2020) . 


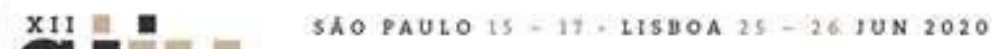

\subsection{Espaços públicos vazios e poluídos}

A localidade possui sérios problemas em relação à coleta de lixo, tornando-se acúmulo causa de poluição e transmissão de doenças. Essa realidade é visualizada nos espaços vazios e nas ruas de toda a Comunidade, principalmente nas áreas mais precárias, onde as pessoas tem menos condições econômicas, residentes na "parte de baixo", conforme por eles mesmos nomeada.

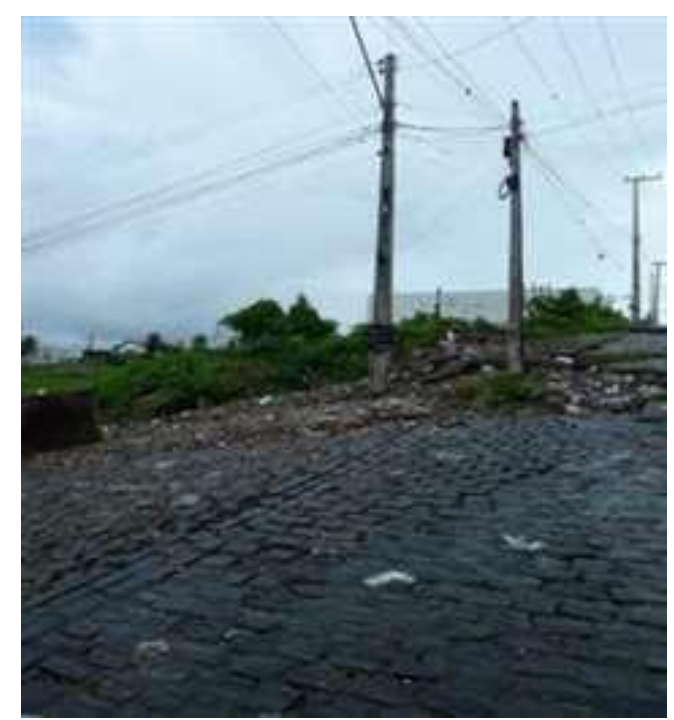

Fig. 16 Espaço público abandonado e com acumulo de resíduos: Arquivo Bons Vizinhos (2020).

\section{5. Área de convivência}

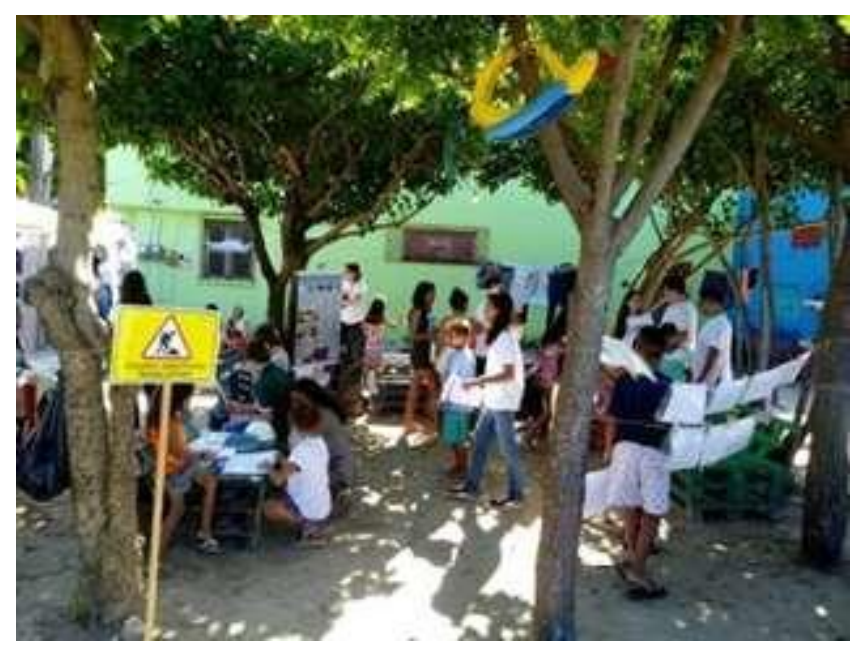

Fig. 17 Espaço Conviva na comunidade do Gengibre: Arquivo Bons Vizinhos (2019).

Com a participação ativa dos universitários da UniFanor, foi criada uma área de convivência arborizada, na Comunidade, conhecida como "Conviva", inspirada nas iniciativas norte-americana, chinesa e paulistana. A iniciativa partiu de uma aluna do Curso de Arquitetura e Urbanismo da Instituição, intervindo junto aos patrocinadores, apresentando Projeto qual se propunha a criação 


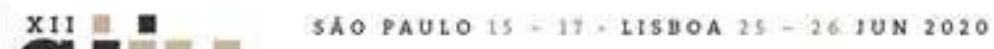

de um ambiente aconchegante para os moradores, com aproveitamento urbanístico de espaço antes ocioso. O "Conviva" é composto de bancos feitos de palletes coloridos, pneus para assento, pula-pula e pequena área verde.

\subsection{Fórum comunitário}

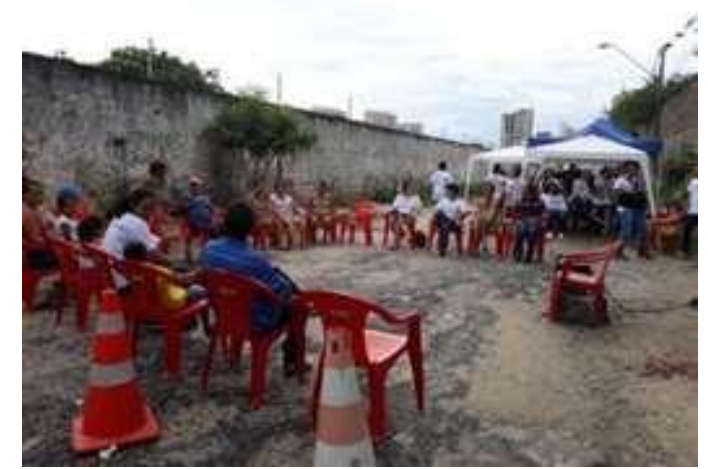

Fig. 18 Fórum Comunitário: Arquivo Bons Vizinhos (2019).

O II Fórum, realizado no dia 30/03/2019, através dos Bons Vizinhos, teve como objetivo reunir os moradores do Gengibre, para ouvi-los, compreender suas dificuldades, acolher suas necessidades sobre o local de moradia e o que nele poderia ser melhorado. No Evento, embora citadas inúmeras deficiências urbanas, tais como reclamações sobre as áreas públicas poluídas, como causas de mau cheiro e doenças, citando-se também a importância da criação de uma área de lazer no local, para que esses espaços não servissem apenas para acúmulo resíduos. O enfoque de nossa pesquisa, porém, foi direcionado especificamente para um diagnóstico urbanístico.

\subsection{Oficina de desenhos}

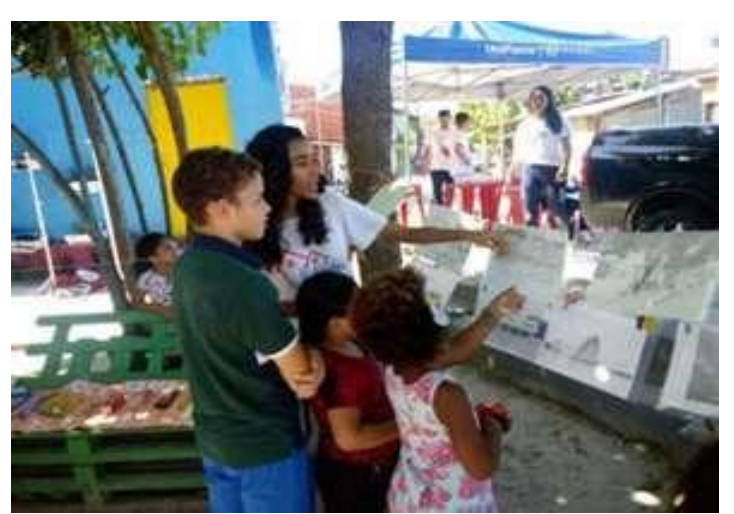

Fig. 19 Feira das Profissões, exposições de desenhos: Arquivo Bons Vizinhos (2019).

Com o objetivo de captar a percepção e a sensibilidade das crianças e dos adolescentes quanto à Comunidade, foi realizada uma Oficina de Desenho, na Feira das Profissões, que ocorreu no dia 25/05/2019. A ação envolveu várias atividades propostas por cursos vinculados ao Programa Bons Vizinhos. 


\section{XII

Primeiramente, ocorreu a exposição de desenhos dos universitários; logo depois, as crianças foram solicitadas a desenhar algum espaço já existente na Comunidade ou o que elas desejam que ali houvesse. Segundo RNCEI V.III (1998), o envolvimento das crianças com diferentes materiais amplia as possibilidades de transformação do mundo. Pensando nisso, a Oficina contou com diversos materiais, dispostos aleatoriamente, de modo que os desenhos e/ou trabalhos gráficos resultassem da tentativa de ampliar as possiblidades de criação, além de exercitar o trabalho coletivo das crianças e dos adolescentes.
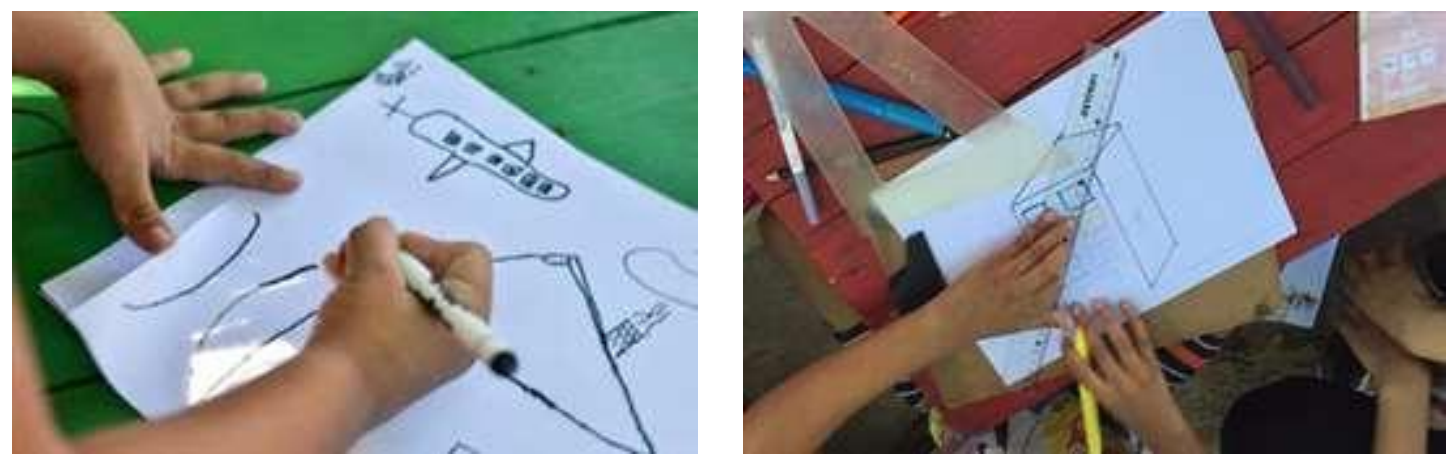

Fig. 20 Desenhos realizados pelas crianças da comunidade: Arquivo Bons Vizinhos (2019).

Gengibre é uma localidade com moradias de características simples, entretanto, foi observado que a maioria dos participantes fez desenhos com atributos não presentes naquele espaço, como é possível observar na imagem acima, no qual uma criança desenhou um edifício e, outra, uma casa com chaminé.

A Oficina de Desenho possibilitou o conhecimento da perspectiva a partir da qual olhava o mundo, uma faixa etária de moradores diferentes, graças à qual ocorreu uma avaliação positiva da ação realizada, já que os moradores que integraram a ação manifestaram participação muito ativa. Abaixo, uma tabela-síntese com as ações realizadas no Gengibre e suas principais considerações.

\begin{tabular}{|c|c|c|c|}
\hline & $\begin{array}{l}\text { Participação dos } \\
\text { moradores }\end{array}$ & Pontos positivos & Pontos negativos \\
\hline $\begin{array}{l}\text { Fór } \\
\text { um } \\
\text { co } \\
\text { mu } \\
\text { nit } \\
\text { ári } \\
\text { o }\end{array}$ & $\begin{array}{l}\text { Pouca participação } \\
\text { dos moradores, } \\
\text { principalmente da } \\
\text { "parte de baixo". }\end{array}$ & $\begin{array}{l}\text { Possibilidade de os moradores } \\
\text { debaterem sobre as carências, } \\
\text { potencialidades e problemas da } \\
\text { comunidade; participação ativa } \\
\text { dos moradores que } \\
\text { compareceram. }\end{array}$ & $\begin{array}{l}\text { Por ser o primeiro fórum } \\
\text { e acontecer na "parte de } \\
\text { cima" compareceram } \\
\text { poucos moradores. }\end{array}$ \\
\hline
\end{tabular}




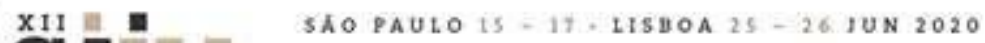

\begin{tabular}{|c|c|c|c|}
\hline $\begin{array}{r}\text { Ofi } \\
\text { cin } \\
\text { a } \\
\text { de } \\
\text { de } \\
\text { se } \\
\text { nh } \\
\text { o }\end{array}$ & $\begin{array}{l}\text { Tomou parte uma } \\
\text { grande quantidade de } \\
\text { crianças, porém } \\
\text { compareceram } \\
\text { poucos adolescentes. }\end{array}$ & $\begin{array}{l}\text { Possibilidade de conhecer a } \\
\text { perspectiva a partir da qual a } \\
\text { comunidade de uma dada faixa } \\
\text { etária percebe o mundo e seus } \\
\text { problemas; } \\
\text { Possibilidade de conhecer as } \\
\text { necessidades de crianças e } \\
\text { adolescentes. }\end{array}$ & $\begin{array}{l}\text { Poucos adolescentes } \\
\text { compareceram, } \\
\text { possivelmente em } \\
\text { virtude do horário em } \\
\text { que foi realizada a } \\
\text { Oficina - e por } \\
\text { mostrarem desinteresse } \\
\text { para a arte do desenho. }\end{array}$ \\
\hline
\end{tabular}

Tabela 01 Análise das atividades realizadas na comunidade do Gengibre: Elaborada pelos autores (2019).

\section{Conclusão}

Por meio dos dados coletados sobre a Comunidade analisada e sobre os conceitos abordados no trabalho, é possível denotar a importância do estudo do tema proposto, sobretudo relevada em se tratando de temática e Comunidade negligenciadas pelas Autoridades Governamentais.

Estando localizada em uma Zona de Preservação Ambiental 1 (ZPA1), a Comunidade do Gengibre é carente da Assistência Pública, não possuindo serviços básicos e nem espaços públicos para lazer. Por falta de assistência, a comunidade possui vazios urbanos que poderiam ser transformadas em áreas úteis, reorganizadas para o uso da população.

A importância de um diagnóstico urbanístico, conduzido a partir do lócus estudado, faz com que visualizemos melhor as reais dificuldades e necessidades dos moradores do local, mediante contato com a população e o desenvolvimento de algumas atividades, graças às quais possamos entender o que realmente se passa com aquela população em seu cotidiano - e o que nele possa eventualmente ser melhorado.

Dessa forma e de acordo com os dados que possibilitaram este mínimo diagnóstico urbanístico da Comunidade do Gengibre, objetivando proposta de requalificação urbana futura, a ser apresentada às Autoridades Governamentais, concluímos que espaços recreativos e de educação, tais como bibliotecas comunitárias, parques infantis, áreas verdes e/ou de recreação e lazer, sejam uma boa sugestão, pois tais Projetos, além de ampliar o contato social entre pessoas, são formas arquitetônico-urbanísticas capazes, senão de solucionar problemas quanto a espaços citadinos mal aproveitados, de humanizar as cidades, ampliando, para as pessoas, sobretudo de baixa renda, o acesso que lhes assiste - e que é-lhes negado - quanto aos usos democráticos dos espaços da cidade. Qualquer cidade. 


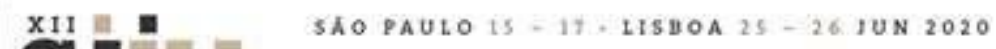

\section{BIBLIOGRAFIA}

7.1.1. Livros e Revistas

BENTO DA SILVA, V. R. (2011). Centro e Periferia em Fortaleza sob a ótica das disparidades na infraestrutura de saneamento básico. Mestrado Acadêmico em Geografia, 28 de fevereiro.

BRASIL. Ministério da Educação e da Cultura. Secretaria de Educação Fundamental. Referencial Curricular Nacional para Educação Infantil. Formação Pessoal e Social: MEC/SEF, 1998b.

COMPANS, R. (2007). A cidade contra a favela. A nova ameaça ambiental. Revista Brasileira de Estudos Urbanos e Regionais (Recife), 83-99.

COSTA GRACE, V. e NASCIMENTO SENA, J. A. (2005). O conceito de favelas e assemelhados sob o olhar do IBGE, das prefeituras do Brasil e da ONU. Anais do X Encontro de Geógrafos da América Latina, 20 a 26 de março.

FERNANDES MARIA, T. e COSTA GAMA-ROSA, R. (2013) As comunidades de Manguinhos na história das favelas no Rio de Janeiro. Revista Tempo (Niterói, Brasil), 117-133.

FERNADES MARIA, T. e COSTA GAMA-ROSA, R. (2010). Cidades e favelas: territórios em disputa. X Encontro Nacional de História Oral, Recife, 26 de abril de 2010.

GOMES, M. F. e QUEIROZ ELIAS, D. R. (2016). Estudo dos Espaços Livres e Áreas de Lazer na Cidade de Araçatuba-SP. Revista online - Caminhos de Geografia (São Paulo), 165-179.

LIMA PINHEIRO, A. (2017). Águas jardim: Uma requalificação Urbana do Canal Jardim América. Trabalho final de Graduação, Junho de 2017.

NASCIMENTO, M. (2010) A favela como expressão dos conflitos no espaço do Rio de Janeiro.

PIZARRO PIMENTEL, E. (2014). Interstícios e Interfaces Urbanos como oportunidades latentes: o caso da Favela de Paraisópolis-SP. Dissertação de Mestrado, 2014.

ROSANA, D. (2005). Intervenção Municipal em Favelas: aprimoramento e limitações. XI Encontro Nacional da Associação Nacional de Pós-Graduação e Pesquisa em Planejamento Urbano e Regional- ANPUR, 23-27 de maio.

SOARES ALVES, J. e PINTO SOUSA MOREIRA, I. (2011). Políticas de erradicação de áreas de risco em Fortaleza (CE): Conflitos e Contradições. XIV Encontro Nacional da Anpur, maio de 2011.

\subsubsection{Fontes eletrônicas}

https://diariodonordeste.verdesmares.com.br/editorias/metro/cidade-2000-perdeu-sua-estruturaoriginal-1.715243 (consulta: 22/02/2020).

https://www.opovo.com.br/noticias/fortaleza/2019/04/25/desabrigadas-apos-cheia-de-lagoa-familias-de-comunidade-em-fortaleza-pedem-ajuda.html (consulta:22/02/2020).

https://www20.opovo.com.br/app/opovo/cotidiano/2017/01/09/noticiasjornalcotidiano,3678717/gengi bre-ocupacao-irregular-sem-solucao-no-bairro-manuel-dias-branco.shtml (consulta:22/02/2020). 


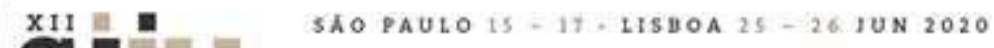

https://cidades.ibge.gov.br/brasil/ce/fortaleza/pesquisa/23/25359 (consulta:22/02/2020).

https://www.fortaleza.ce.gov.br/noticias/defesa-civil-de-fortaleza-realiza-semana-municipal-dereducao-de-desastres (consulta:22/02/2020).

https://portal.seuma.fortaleza.ce.gov.br/fortalezaonline/portal/legislacao/Consulta_Adequabilidade/1 Lei_Complementar_N236\%20de_11_de\%20agosto_de_2017_Lei_de_Parcelamento_Uso_Ocupac ao_do_Solo-LUOS.pdf (consulta:22/02/2020).

http:/themwordblog.blogspot.com/2013/01/take-library-to-people.html (consulta:08/07/2020).

https://arquiteturaeconstrucao.abril.com.br/cidade/na-onda-das-minipracas-

paulistanas/amp/(consulta: 08/07/2020).

https://www.todeschini.com.br/blog/urbanismo-tatico-ja-ouviu-falar/ (consulta:08/07/2020).

https://www.archdaily.com.br/br/918621/pixeland-100architects (consulta:08/07/2020).

https://www.streetlab.org/uni-project/ (consulta:08/07/2020).

https://www.vitruvius.com.br/revistas/read/arquitextos/19.219/7103 (consulta:08/07/2020). 